\title{
The potential of hybrid breeding to enhance leaf rust and stripe rust resistance in wheat
}

\author{
Ulrike Beukert ${ }^{1}$ - Guozheng Liu ${ }^{2}$. Patrick Thorwarth ${ }^{3}$ - Philipp H. G. Boeven ${ }^{3}$. C. Friedrich H. Longin ${ }^{3}$. \\ Yusheng Zhao ${ }^{4} \cdot$ Martin Ganal $^{5} \cdot$ Albrecht Serfling $^{1} \cdot$ Frank Ordon $^{1} \cdot$ Jochen C. Reif ${ }^{4}$
}

Received: 7 August 2019 / Accepted: 31 March 2020 / Published online: 12 April 2020

(c) The Author(s) 2020

\begin{abstract}
Key message Hybrid wheat breeding is a promising strategy to improve the level of leaf rust and stripe rust resistance in wheat.

Abstract Leaf rust and stripe rust belong to the most important fungal diseases in wheat production. Due to a dynamic development of new virulent races, epidemics appear in high frequency and causes significant losses in grain yield and quality. Therefore, research is needed to develop strategies to breed wheat varieties carrying highly efficient resistances. Stacking of dominant resistance genes through hybrid breeding is such an approach. Within this study, we investigated the genetic architecture of leaf rust and stripe rust resistance of 1750 wheat hybrids and their 230 parental lines using a genome-wide association study. We observed on average a lower rust susceptibility for hybrids in comparison to their parental inbred lines and some hybrids outperformed their better parent with up to 56\%. Marker-trait associations were identified on chromosome 3D and $4 \mathrm{~A}$ for leaf rust and on chromosome $2 \mathrm{~A}, 2 \mathrm{~B}$, and $6 \mathrm{~A}$ for stripe rust resistance by using a genome-wide association study with a Bonferroni-corrected threshold of $P<0.10$. Detected loci on chromosomes 4A and 2A were located within previously reported genomic regions affecting leaf rust and stripe rust resistance, respectively. The degree of dominance was for most associations favorable in the direction of improved resistance. Thus, resistance can be increased in hybrid wheat breeding by fixing complementary leaf rust and stripe rust resistance genes with desired dominance effects in opposite parental pools.
\end{abstract}

Communicated by Urmil Bansal.

Electronic supplementary material The online version of this article (https://doi.org/10.1007/s00122-020-03588-y) contains supplementary material, which is available to authorized users.

Jochen C. Reif

reif@ipk-gatersleben.de

1 Institute for Resistance Research and Stress Tolerance, Julius Kuehn-Institute (JKI), Erwin-Baur-Straße 27, 06484 Quedlinburg, Germany

2 BASF Agricultural Solutions Belgium NV, Technologiepark 101, 9052 Zwijnaarde, Ghent, Belgium

3 State Plant Breeding Institute, University of Hohenheim, Fruwirthstraße 21, 70593 Stuttgart, Germany

4 Leibniz Institute of Plant Genetics and Crop Plant Research (IPK), Corrensstraße 3, 06466 Stadt Seeland OT Gatersleben, Germany

5 TraitGenetics GmbH, Am Schwabeplan 1b, 06466 Stadt Seeland, OT Gatersleben, Germany

\section{Introduction}

Wheat (Triticum aestivum L.) is an important crop in the world with an annual production of $\sim 770$ million tons harvested on 220 million hectares in 2017 (FAO 2019). Wheat is a central source of calories and proteins for human nutrition and plays therefore an important role to feed the earth's growing population (Peña-Bautista et al. 2017). Leaf rust caused by Puccinia triticina and stripe rust caused by Puccinia striiformis $\mathrm{f}$. sp. tritici belong to the most important fungal diseases of wheat (Huerta-Espino et al. 2011; Wellings 2011). Leaf rust and stripe rust show enormous genetic diversity due to phases of sexual recombination within their life cycle. The naturally occurring rust population is subject of local adaption, stepwise evolution, and a high selection pressure leading to the dynamic development of new pathotypes (Bolton et al. 2008; Schwessinger 2017). Therefore, epidemics appear in high frequency resulting in yield losses up to $70 \%$ (Chen 2005; Huerta-Espino et al. 2011) as well as a reduced grain quality (Prescott et al. 1986). 
The use of effective resistance genes against rust diseases in wheat cultivars is a sustainable and environment-friendly solution to reduce yield and quality losses. Currently there are around 90 and 80 resistance genes for leaf rust ( $L r$-genes) and stripe rust ( $\mathrm{r}$-genes) known, respectively (McIntosh et al. 1995, 2005, 2009, 2013, 2015, 2017). The majority of those cause race-specific resistance mostly leading to hypersensitive cell death (Bolton et al. 2008; Singh et al. 2005). In contrast to this, very few genes are known, which are non-race-specific and result in a quantitative reduction in the infection level at the adult plant stage like Lr34 (Bolton et al. 2008), Yr18, or Yr29 (Chen 2013). Race-specific resistance causes complete resistance at the seedling stage and is based on a single gene, which can be easily overcome by fast developing rust populations (Bolton et al. 2008; Schwessinger 2017).

To promote the effectiveness of resistance, breeders aim to pyramidize resistance genes within the same cultivar (Singh et al. 2005). Stacking dominant resistance genes can be most efficiently implemented through hybrid breeding (Longin et al. 2012). Currently, hybrid breeding is implemented in several wheat breeding programs, because it promises to boost yield and yield stability (Jiang et al. 2017; Longin et al. 2013; Mühleisen et al. 2014). The potential of stacking resistance genes via hybrid breeding strongly depends on the frequency of genes displaying complete dominance. Nevertheless, there is a lack of background knowledge on the genetic architecture and degree of dominance of resistance against rust diseases in wheat.

Our study is based on a comprehensive hybrid wheat population including 1750 hybrids derived from crossing of 189 female and 41 male lines using an incomplete factorial mating design. The parents and hybrids were evaluated in multi-environment field trials for leaf rust and stripe rust resistance and genotyped using a $15 \mathrm{k}$ SNP array. The objectives of this study were to (1) identify single nucleotide polymorphisms (SNPs) associated with adult plant resistance against leaf rust and stripe rust by performing genome-wide association mapping, (2) investigate the genetic architecture plus the degree of dominance of leaf rust and stripe rust resistance within a European hybrid wheat population, and
(3) evaluate the resistance improvement based on a hybrid breeding strategy.

\section{Materials and methods}

\section{Plant material}

This study comprised 189 female and 41 male elite winter wheat lines and their 1750 single-cross hybrids, which were generated following an incomplete factorial mating design using chemical hybridization agents. The elite lines were provided by the following 13 wheat breeding companies: BASF Agricultural Solutions GmbH, Deutsche Saatveredelung AG, KWS LOCHOW GmbH, Limagrain GmbH, Pflanzenzucht Oberlimpurg, RAGT-Saaten GmbH, Saatzucht Bauer GmbH, Saatzucht Josef Breun GmbH \& Co. KG, Saatzucht Streng-Engelen GmbH \& Co. KG, Secobra Saatzucht GmbH, Strube Research GmbH \& Co. KG, Syngenta Seeds GmbH, and W. von Borries-Eckendorf GmbH \& Co. KG. Details on the crossing design have been described elsewhere (Boeven et al. 2020).

\section{Field trials and experimental design}

Hybrids and their parental lines were grown in multi-location, unreplicated field trials in two years $(2016,2017)$ to monitor their leaf rust and stripe rust severity. Leaf rust data were collected in seven different environments while stripe rust was observed in five environments (Table 1).

The field trials were unreplicated and included the same 11 checks (JB Asano, Julius, RGT Reform, Colonia, KWS Loft, Rumor, Tobak, Elixer, Hybred, Hystar, LG Alpha) for every environment. Field trials were randomized following an $\alpha$-design. Infection of genotypes with leaf rust and stripe rust occurred naturally and was scored at the date of flowering (EC stage 65) on the flag leaf. An ordinal scale from 1 to 9 on the basis of the Bundessortenamt (2000) was used in order to score infections, where one stands for minimal symptoms and nine indicates extensive disease symptoms.
Table 1 Characterization of environments, in which leaf rust and stripe rust severity were evaluated

\begin{tabular}{lllllll}
\hline Location & Year & Latitude & Longitude & Soil type & Leaf rust & Stripe rust \\
\hline Asendorf & 2016 & 52.738315 & 9.006696 & Luvisol & & Yes \\
Feldkirchen & 2017 & 48.29080 & 11.55063 & Cambisol & Yes & \\
Hadmersleben & 2016 & 51.5837 & 11.1751 & Deep loam & Yes & Yes \\
Hadmersleben & 2017 & 51.5837 & 11.1751 & Deep loam & Yes & Yes \\
Leopoldshöhe & 2017 & 51.58456 & 8.40396 & Luvisol & Yes & \\
Northeim & 2016 & 51.44240 & 9.54367 & Loess-/Loamsoil & Yes & \\
Rosenthal & 2016 & 52.181889 & 10.105288 & Chernozem & Yes & Yes \\
Söllingen & 2017 & 52.097285 & 10.925914 & Chernozem & Yes & Yes \\
\hline
\end{tabular}




\section{Analysis of phenotypic data}

Detection of outliers and estimation of variance components was conducted implementing the following mixed linear model:

$y_{i j k l}=\mu+e_{l}+b_{k \mid l}+g_{i j}+m_{i}+f_{j}+s_{i j}+(m e)_{i l}+(f e)_{j l}+\varepsilon_{i j k l}$,

where $y_{i j k l}$ is the performance of lines $(i=j)$ or hybrids $(i \neq j)$ arising from a cross between the $i$ th parent with the $j$ th parent in the $k$ th incomplete block in the $l$ th environment. $\mu$ refers to the overall population mean. $e_{l}$ is the effect of the $l$ th environment, i.e., location by year combination, $b_{k \mid l}$ represents the block effect of the $k$ th block nested within the $l$ th environment. $g_{i j}$ was only modeled for the parental lines and stands for their genotypic effect. $m_{i}$ and $f_{j}$ were modeled for hybrids and are the GCA effects of the $i$ th and $j$ th of the male and female parent, respectively, $s_{i j}$ symbolizes the SCA effect of the cross between the $i$ th and $j$ th parents. $(m e)_{i l}$ as well as $(f e)_{j l}$ which were only modeled for hybrids, are the interaction between the GCA effect of the $i$ th and $j$ th parent with the $l$ th environment., $\varepsilon_{i j k l}$ refers to the corresponding residuals. All effects except the intercept were modeled as random effects.

A second model was used to obtain best linear unbiased estimations (BLUEs) across environments.

$y_{i k l}=\mu+g_{i}+e_{l}+b_{k \mid l}+\varepsilon_{i k l}$,

where $y_{i k l}$ is the phenotypic observation of the $i$ th genotype in the $k$ th block at the $l$ th environment. $\mu$ is the intercept, $g_{i}$ symbolizes the genotypic effect of the $i$ th individual and $e_{l}$ stands for the effect of the $l$ th environment. $b_{k \mid l}$ represents the block effect of the $k$ th block nested within the $l$ th environment, while $\varepsilon_{i k l}$ is the residual error associated with the observation $y_{i k l}$. The genotype effect was assumed as fixed to estimate the BLUEs, while all remaining effects were treated as random. Broad-sense heritability was calculated using variance component estimates of the first model as:

$h^{2}=\frac{\sigma_{\text {Genotype }}^{2}}{\sigma_{\text {Phenotype }}^{2}}=\frac{\sigma_{\text {Genotype }}^{2}}{\sigma_{\text {Genotype }}^{2}+\frac{\sigma_{G \times E}^{2}}{\text { No. of environment }}+\frac{\sigma_{\text {error }}^{2}}{\text { No. of environment }}}$

Variance of genotypes was estimated as the sum of variance components of GCA and SCA effects. Variance of interaction effects of genotypes and environments were estimated as the sum of variance of GCA-by-environment interaction effects. Heritability for single locations was estimated following the concept of genomic heritability to evaluate the quality of field trials. This was done by estimating the prediction abilities applying fivefold crossvalidation as outlined in detail elsewhere (Schulthess et al. 2018).

\section{Genotypic analysis}

The extraction of DNA was conducted in compliance with known standard procedures (Stein et al. 2001). Parental lines were genotyped using a $15 \mathrm{k}$ single-nucleotide-polymorphism (SNP) array containing a subset of the wheat $90 \mathrm{k}$ Illumina Infinium array (Wang et al. 2014). Composition of the $15 \mathrm{k}$ SNP chip and the genotyping was implemented by TraitGenetics GmbH (http://www.traitgenetics. com). Population structure of the parental pools was examined by calculating their Rogers' distances in addition to perform a principle coordinate analysis (PCoA). Genotypic information was imputed in accordance to He et al. (2015). Quality filtering was performed whereby redundant markers, markers with missing values $>5 \%$, heterozygosity of $>5 \%$ in inbred material, or a minor allele frequency (MAF) of $<5 \%$ were excluded. After this selection, 10,453 markers and 1768 genotypes of high quality were left and used for association mapping. The procedure for the association mapping was previously described in detail by Liu et al. (2016). We applied the following model:

$Y=\mu+A a+D d+Z z+\varepsilon$,

where $Y$ describes BLUEs across the locations, $\mu$ is the vector of intercept effects, $a$ symbolizes the vector of additive effects, $d$ is a vector of dominance effects, $z$ is representing the vector of polygene background effects and $\varepsilon$ stands for the vector of residual effects. $A, D$, and $Z$ were incidence matrices, which relates the BLUEs to the vectors $a, d$, and $z$. Further, a Bonferroni-corrected threshold of $P<0.10$ was applied to control for multiple testing. All statistical analyses were done using the software $\mathrm{R}$ ( $\mathrm{R}$ Development Core Team 2014) and the package ASReml-R 3.0 (Gilmour et al. 2009). The minor allele frequency (MAF) for significant associated markers was calculated and the linkage disequilibrium (LD) was assessed by the LD measure $r^{2}$ (Weir 1996).

\section{Results}

The hybrids and their parental lines were evaluated for leaf rust severity in seven different environments. The estimated heritability for parents was $h^{2}=0.82$ and for hybrids $h^{2}=0.66$. The sum of variance of GCA effects was two times larger than the variance of SCA effects (Suppl. Table 1). Leaf rust severity of female parents ranged from 2 to 5 with a mean of 3.21 and male lines ranged from 3 to 4 and averaged at 3.23 (Fig. 1; Suppl. Table 2). The hybrid population covered a range from 2 to 5 with a mean value of 3.10 . The hybrids outperformed the better parent by an average of 0.28 (Suppl. Figure 1; Suppl. Table 2). 

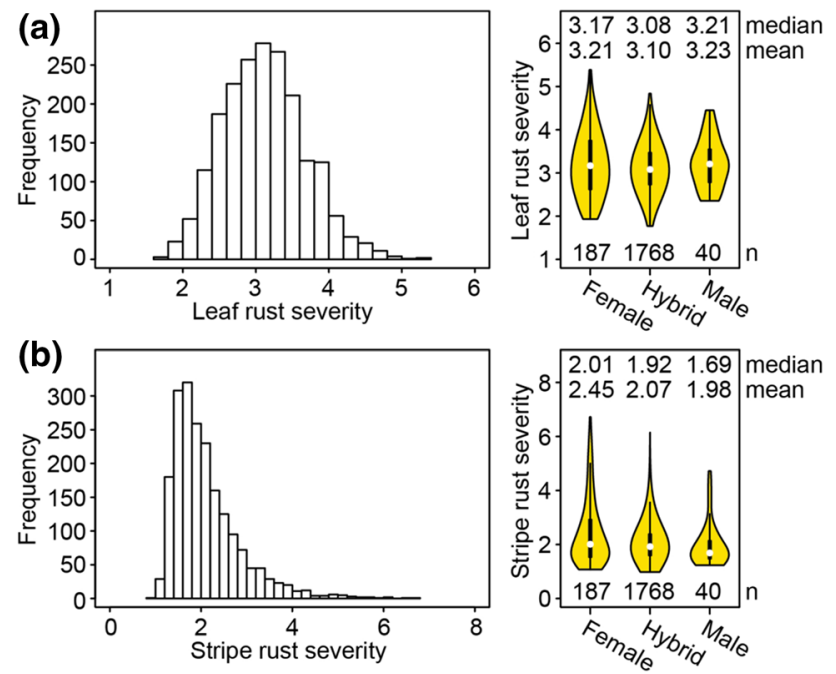

Fig. 1 Summary of phenotypic data for leaf rust (a) and stripe rust severity (b). Histograms showing genotype frequencies for scoring grades one to nine on the $\mathrm{x}$-axis for leaf rust and stripe rust severity. In addition, violin plots showing the distribution for rust severity clustered for single parental pools and hybrids

The assessment of different genotypes for stripe rust severity was conducted in five environments resulting in a heritability for parents and hybrids of $h^{2}=0.92$ and $h^{2}=0.72$, respectively. The sum of variance of GCA effects was five times larger than the variance of SCA effects (Suppl. Table 1). The parental pool of females showed a wide distribution from 1 to 7 with an average of 3.45 , while male lines ranged from 1 to 5 with a mean of 1.98 . Hybrid scores were ranging from 1 to 6 with a mean of 2.07 (Fig. 1; Suppl. Table 2). The stripe rust distribution was skewed towards resistance, which can be explained by intensive selection of parental lines for this trait. The hybrids outperformed the better parent by an average of 0.40 (Suppl. Figure 1; Suppl. Table 2).

Parental lines were genotyped with genome-wide distributed SNP markers. We examined the population structure and relatedness of all parental lines by calculating their Rogers' distances (Suppl. Figure 2) and implemented a PCoA (Suppl. Figure 3). Both procedures indicated that the population of parental lines is not structured and distinct parental pools are missing. Therefore, we corrected in the genome-wide association mapping for relatedness using a kinship matrix and ignored terms to correct for effects of subpopulations.

Genome-wide association scans were performed with the high-quality data of 10,453 markers using a significance threshold of $P<0.10$ applying Bonferroni correction for multiple testing. We observed only a few loci with significant additive effects on leaf rust severity. In contrast, there were several loci exhibiting significant
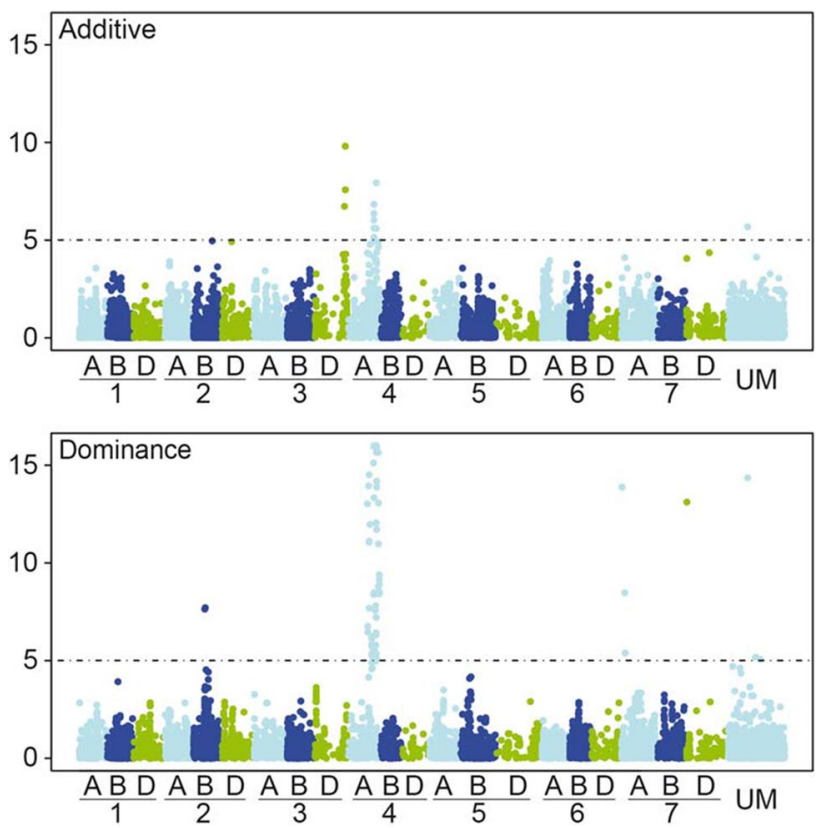

Fig. 2 Manhattan plots from the genome-wide association scan for additive and dominance effects on leaf rust severity. The dashed horizontal line symbolizes the significant threshold of $P<0.10$ applying Bonferroni correction. Unmapped markers were outlined under "UM"

dominance effects (Fig. 2). Putative quantitative trait loci (QTL) affecting leaf rust resistance were detected on chromosomes $3 \mathrm{D}$ and $4 \mathrm{~A}$ with respect to their additive effects and on chromosomes $2 \mathrm{~B}, 4 \mathrm{~A}$, and $7 \mathrm{~A}$ for dominance effects. The strongest association for leaf rust resistance was identified for dominance effects by a major peak of significantly associated markers on chromosome 4A. In total, there were 61 significantly associated markers on chromosome $4 \mathrm{~A}$, which were all located between 104 and $166 \mathrm{cM}$ according to the genetic linkage map of Wang et al. (2014). Those associated markers could be assigned to 22 or 47 unique groups based on similar genetic or physical positions. Most of the identified markers with an effect on leaf rust resistance are physically located on chromosome $4 \mathrm{~A}$ in the genomic region between 627,815 and 742,567 Mbp of the wheat reference genome (International Wheat Genome Sequencing Consortium (IWGSC) 2018). Combining the marker data with the wheat reference genome was done to compare associated loci with genomic regions of previous known function. Four detected significant markers on chromosome 4A located between 707,043 and $726,215 \mathrm{Mbp}$ in addition to two markers on 2B placed at 157,694 and $442,797 \mathrm{Mbp}$ were identified within the regions of previous known NBSLRR genes, while detected markers on chromosome 2B and $6 \mathrm{~A}$ are located within regions of previous known protein kinase genes (Table 2). Most of the identified significant markers showed desired negative dominance effects 
Table 2 Comparison of detected markers with a significant effect on leaf rust severity with the location of previously known resistance genes within the reference genome

\begin{tabular}{|c|c|c|c|c|c|c|c|}
\hline \multirow[t]{2}{*}{ Marker (ID of reference gene) } & \multirow[t]{2}{*}{ Type } & \multirow[t]{2}{*}{ Chr. } & \multicolumn{2}{|c|}{ Physical Marker Pos. } & \multirow[t]{2}{*}{ Gene function } & \multicolumn{2}{|c|}{ Physical Gene Pos. } \\
\hline & & & Start (bp) & End (bp) & & Start (bp) & End (bp) \\
\hline $\begin{array}{l}\text { RAC875_c1226_652 } \\
\quad \text { (TraesCS2B01G182800) }\end{array}$ & dom & $2 \mathrm{~B}$ & $157,693,634$ & $157,693,534$ & $\begin{array}{l}\text { NBS-LRR disease resistance } \\
\text { protein }\end{array}$ & $157,688,966$ & $157,696,282$ \\
\hline $\begin{array}{l}\text { wsnp_JD_c9251_10121369 } \\
\text { (TraesCS2B01G309900) }\end{array}$ & dom & 2B & $442,796,772$ & $442,796,972$ & Protein kinase & $442,795,590$ & $442,798,055$ \\
\hline $\begin{array}{l}\text { wsnp_Ex_c4331_7808746 (TraesC- } \\
\text { S4A01G437200) }\end{array}$ & add & $4 \mathrm{~A}$ & $707,042,951$ & $707,043,104$ & $\begin{array}{l}\text { Protein enhanced disease resistance } \\
\text { 2-like }\end{array}$ & $707,040,590$ & $707,048,030$ \\
\hline $\begin{array}{l}\text { Excalibur_rep_c112888_602 } \\
\text { (TraesCS4A01G446700) }\end{array}$ & add & $4 \mathrm{~A}$ & $714,176,967$ & $714,176,867$ & $\begin{array}{l}\text { Disease resistance protein (TIR- } \\
\text { NBS-LRR class) family }\end{array}$ & $714,176,254$ & $714,180,521$ \\
\hline $\begin{array}{l}\text { RAC875_rep_c69632_65 (TraesC- } \\
\text { S4A01G446700) }\end{array}$ & add & $4 \mathrm{~A}$ & $714,179,046$ & $714,179,146$ & $\begin{array}{l}\text { Disease resistance protein (TIR- } \\
\text { NBS-LRR class) family }\end{array}$ & $714,176,254$ & $714,180,521$ \\
\hline $\begin{array}{l}\text { BobWhite_c47168_598 (TraesC- } \\
\text { S4A01G461700) }\end{array}$ & add & $4 \mathrm{~A}$ & $726,214,991$ & $726,214,891$ & NBS-LRR resistance-like protein & $726,212,910$ & $726,217,457$ \\
\hline $\begin{array}{l}\text { BobWhite_c47168_289 (TraesC- } \\
\text { S4A01G461700) }\end{array}$ & add & $4 \mathrm{~A}$ & $726,215,300$ & $726,215,200$ & NBS-LRR resistance-like protein & $726,212,910$ & $726,217,457$ \\
\hline $\begin{array}{l}\text { wsnp_RFL_Contig4456_5258284 } \\
\text { (TraesCS6A01G401200) }\end{array}$ & add & $6 \mathrm{~A}$ & $609,820,815$ & $609,820,915$ & $\begin{array}{l}\text { Leucine-rich repeat receptor-like } \\
\text { protein kinase family protein }\end{array}$ & $609,813,988$ & $609,821,699$ \\
\hline
\end{tabular}
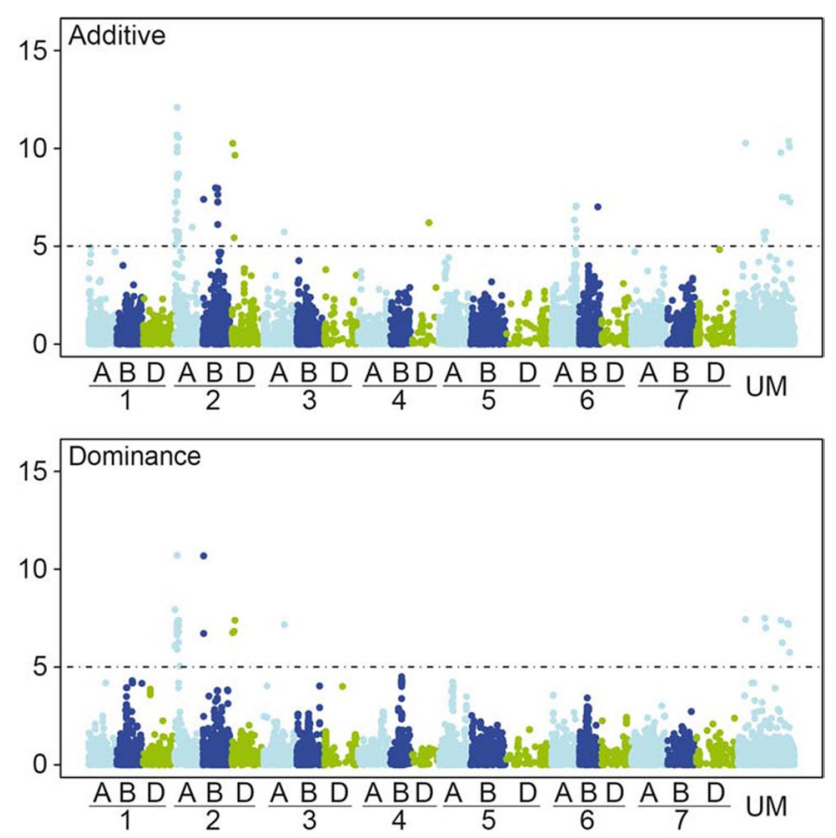

Fig. 3 Manhattan plots of the genome-wide association scan for additive and dominance effects on stripe rust severity. The dashed horizontal line symbolizes the significant threshold of $P<0.10$ applying Bonferroni correction

(Suppl. Table 3). Based on the implemented analyses, putative QTLs were identified on chromosomes $2 \mathrm{~B}, 3 \mathrm{D}$, $4 \mathrm{~A}$, and $7 \mathrm{~A}$.

Several loci with significant additive effects, but only a few with significant dominance effects on stripe rust severity were detected (Fig. 3). Strong associations with major peaks of significantly associated markers were identified on chromosomes $2 \mathrm{~A}$ and $2 \mathrm{~B}$ for both, additive and dominance effects and on chromosome $6 \mathrm{~A}$ for additive effects. We detected 25 significantly associated markers on chromosome 2A, which are located between 2.9 and $29.1 \mathrm{cM}$ corresponding to the genetic linkage map of Wang et al. (2014). The majority of identified markers on chromosome $2 \mathrm{~A}$, which were associated with stripe rust resistance were physically located in the genomic region between 2478 and 19,126 Mbp of the wheat reference genome (IWGSC 2018). The referred physical regions were used to identify significant associated markers related to genome regions with reported resistance functions. A few detected significant markers were located in the regions of previously known NBS-LRR genes on chromosome 2A (Table 3) and may be considered as possible candidate genes for different $Y r$-genes. Most of the identified significant markers showed desired negative dominance effects (Suppl. Table 4).

By the analysis of the linkage disequilibrium (LD), patterns among significantly associated markers were determined using the squared Pearson's correlation coefficient $\left(r^{2}\right)$ among the SNP markers (Figs. 4, 5; Suppl. Figures 4, 5). The markers can be clustered into two groups, while there is a high LD within each group and moderate LD between the groups. Comparing the phenotypic information for the two rust diseases unraveled an absence of a correlation between leaf rust and stripe rust severity (Fig. 6). Further on, the few markers explaining the highest phenotypic variance for leaf rust and stripe rust resistance were used to examine the dominance degree (Fig. 7). The degree of dominance is high ranging for the observed markers from partial dominance to overdominance. 
Table 3 Comparison of detected markers with a significant effect on stripe rust severity with the location of previously known resistance genes within the reference genome

\begin{tabular}{|c|c|c|c|c|c|c|c|}
\hline \multirow[t]{2}{*}{ Marker (ID of reference gene) } & \multirow[t]{2}{*}{ Type } & \multirow[t]{2}{*}{ Chr. } & \multicolumn{2}{|c|}{ Physical Marker Pos. } & \multirow[t]{2}{*}{ Gene function } & \multicolumn{2}{|c|}{ Physical Gene Pos. } \\
\hline & & & Start (bp) & End (bp) & & Start (bp) & End (bp) \\
\hline $\begin{array}{l}\text { BS00068050_51 (TraesC- } \\
\text { S2A01G016200) }\end{array}$ & add & $2 \mathrm{~A}$ & $7,514,010$ & $7,514,110$ & $\begin{array}{l}\text { NB-ARC domain-containing disease } \\
\text { resistance protein }\end{array}$ & $7,513,301$ & $7,514,256$ \\
\hline $\begin{array}{l}\text { BobWhite_c12426_84 (TraesC- } \\
\text { S2A01G030000) }\end{array}$ & add/dom & $2 \mathrm{~A}$ & $13,814,670$ & $13,814,570$ & NBS-LRR-like resistance protein & $13,811,892$ & $13,815,254$ \\
\hline $\begin{array}{l}\text { CAP12_c259_307 (TraesC- } \\
\text { S2A01G037200) }\end{array}$ & dom & $2 \mathrm{~A}$ & $15,875,831$ & $15,875,893$ & NBS-LRR resistance-like protein & $15,874,900$ & $15,876,274$ \\
\hline $\begin{array}{l}\text { D_contig01272_220 (TraesC- } \\
\text { S2A01G053200) }\end{array}$ & add/dom & $2 \mathrm{~A}$ & $21,262,837$ & $21,263,050$ & NBS-LRR disease resistance protein & $21,261,141$ & $21,264,604$ \\
\hline
\end{tabular}

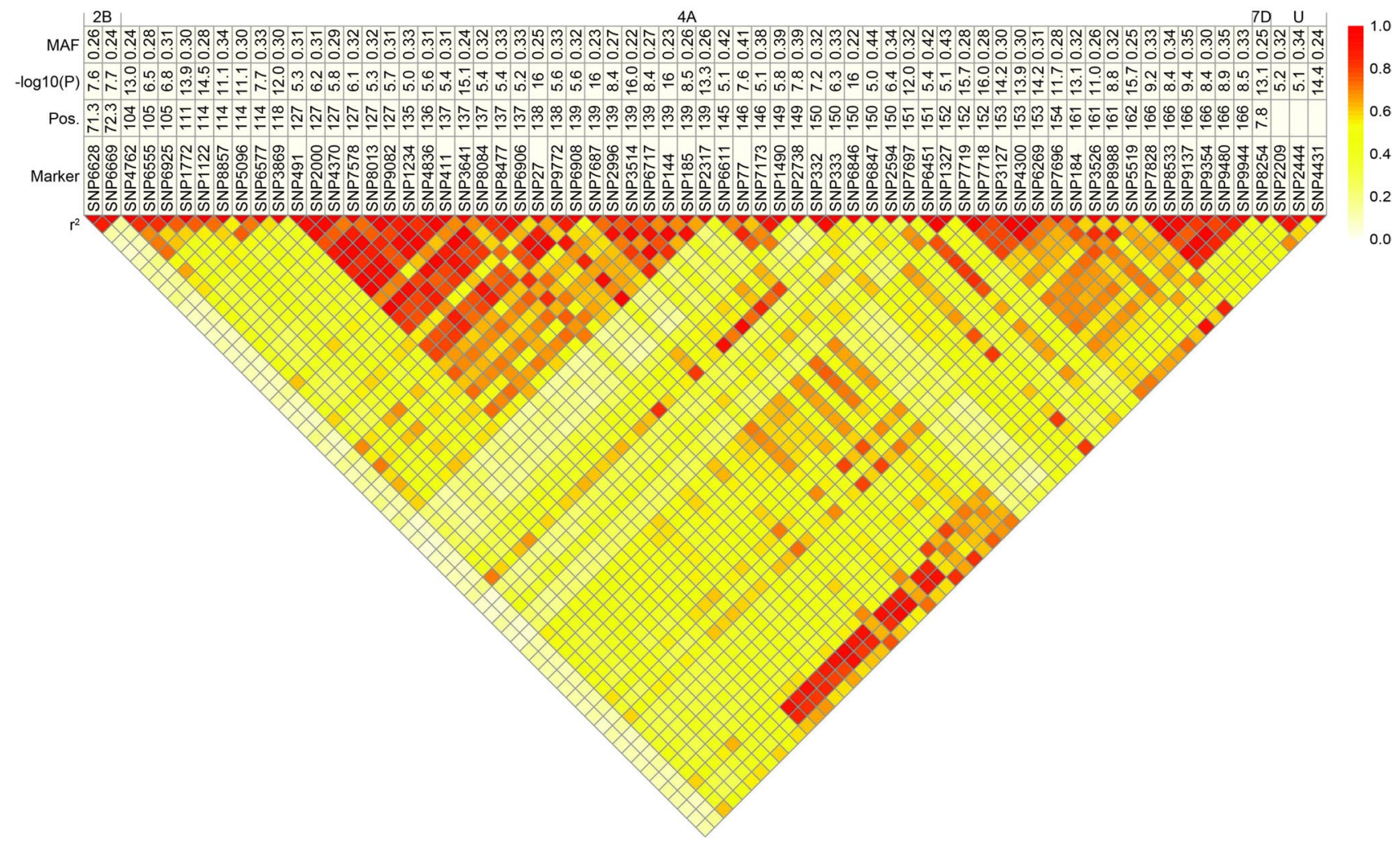

Fig. 4 SNPs with dominant effects for leaf rust severity. Table including minor allele frequency (MAF), significance value $(-\log 10(\mathrm{P}))$, and genetic map position of respective SNP markers that contribute

\section{Discussion}

During the last decade, intensive research and development efforts have been spent to establish hybrid breeding programs for self-pollinating species. In comparison to their parental inbred lines, wheat hybrids showed on average around $10 \%$ of grain yield increase (Longin et al. 2013) and a higher yield stability (Mühleisen et al. 2014). Furthermore, wheat hybrids were on average less significantly to the dominant genetic variation of leaf rust severity. The heat plot presents the linkage disequilibrium (LD) measured as squared Pearson's correlation coefficients $\left(r^{2}\right)$ among SNP markers

susceptible against biotic and abiotic stresses (Gowda et al. 2014; Longin et al. 2013; Miedaner et al. 2013; Zhao et al. 2013) and allow to stack major dominant genes during the breeding process (Longin et al. 2012). Leaf rust and stripe rust belong to the most important fungal diseases of wheat (Huerta-Espino et al. 2011; Wellings 2011). Due to a continuous development of naturally occurring rust populations, epidemics appear in high frequency and can cause yield losses of up to $70 \%$ (Chen 2005; HuertaEspino et al. 2011) as well as a reduction in grain quality 


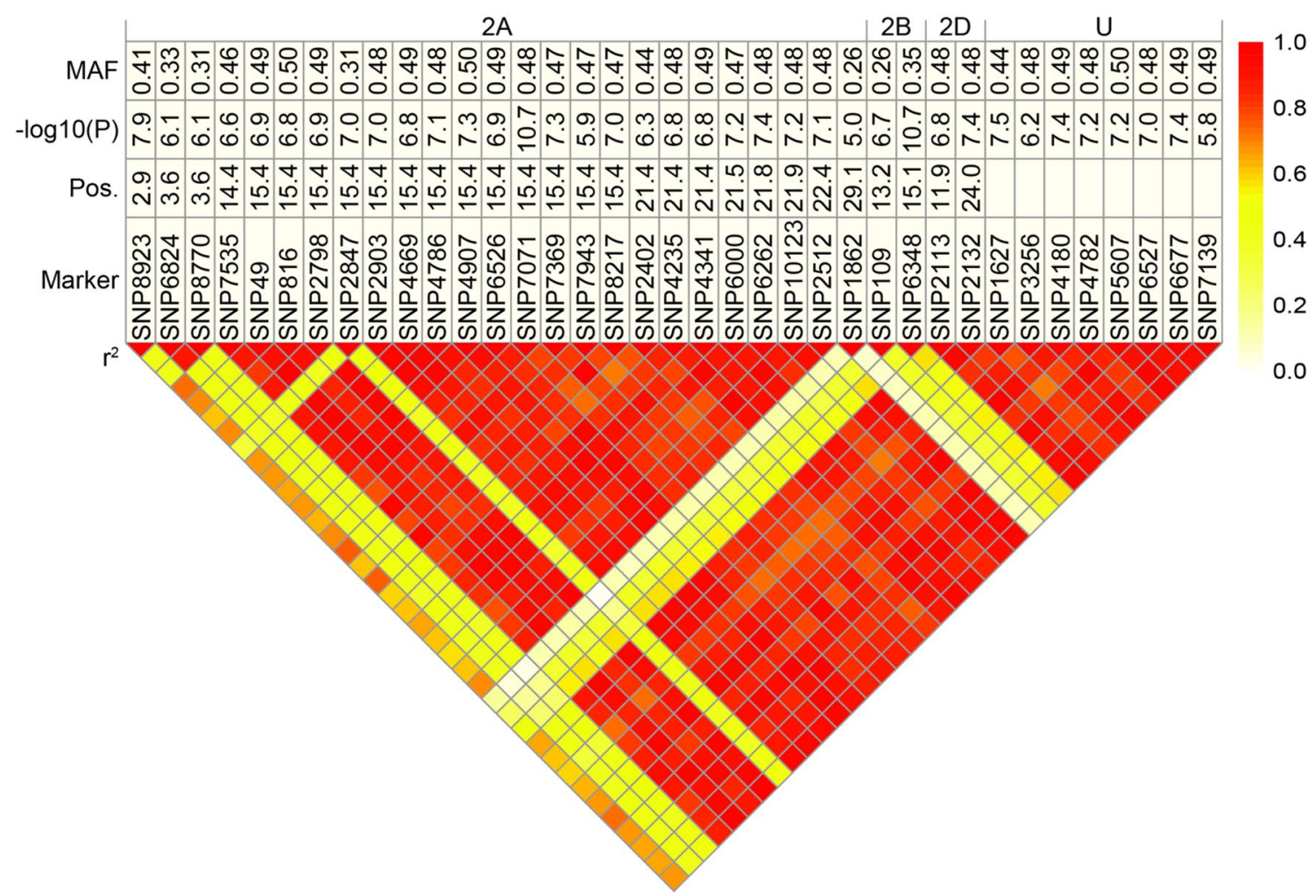

Fig. 5 SNPs with dominance effects for stripe rust severity. Table including minor allele frequency (MAF), significance value $(-\log$ $10(\mathrm{P})$ ), and genetic map position of respective SNP markers that contribute significantly to the dominant genetic variation of stripe rust

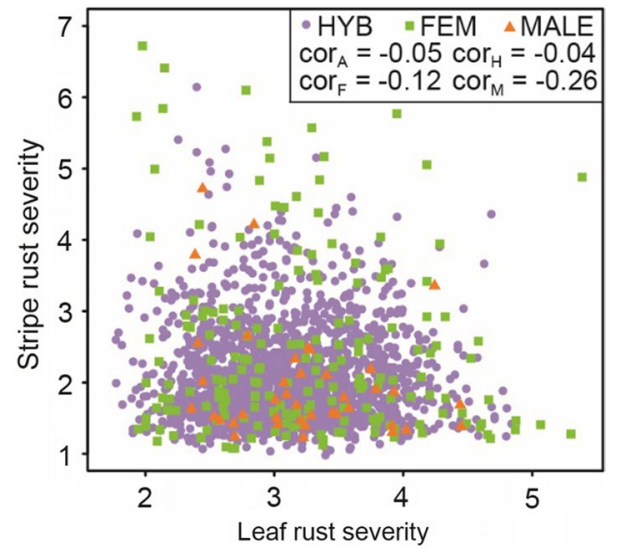

Fig. 6 Plot of BLUEs for each phenotyped genotype comprising parents and hybrids. The $\mathrm{x}$-axis represents the score for leaf rust severity while on the y-axis the stripe rust severity is shown. Furthermore, the correlation between leaf rust and stripe rust severity for parental groups, hybrids, and the whole population is presented

(Prescott et al. 1986). In this study, we explored the resistance of hybrids against leaf rust and stripe rust in comparison to their parental inbred lines. Phenotypic data were severity. The heat plot presents the linkage disequilibrium (LD) measured as squared Pearson's correlation coefficients $\left(r^{2}\right)$ among SNP markers

collected from 1750 hybrids and 230 parental lines and were combined with genotypic marker information to elucidate the genetic architecture by performing genome-wide association mapping.

\section{Intensive phenotyping resulted in precise estimates of leaf rust and stripe rust severity}

Phenotyping for leaf rust and stripe rust resistance was done under natural infection conditions in field trials across seven and five environments, respectively. The present conditions led to natural infections with leaf rust and stripe rust within each field trial. The quality of field trials was evaluated by analyzing single locations and studying the genomic heritability within each location. The minimum value observed for genomic heritability amounted to 0.37 with a mean of 0.57 . We consider this as an indicator for excellent testing conditions. For the comparison with other studies, the plotbased heritability for hybrids was estimated and showed values of 0.22 and 0.34 for leaf rust and stripe rust, respectively. Longin et al. (2013) observed comparable values for resistance against stripe rust $(0.25)$, powdery mildew $(0.49)$, 

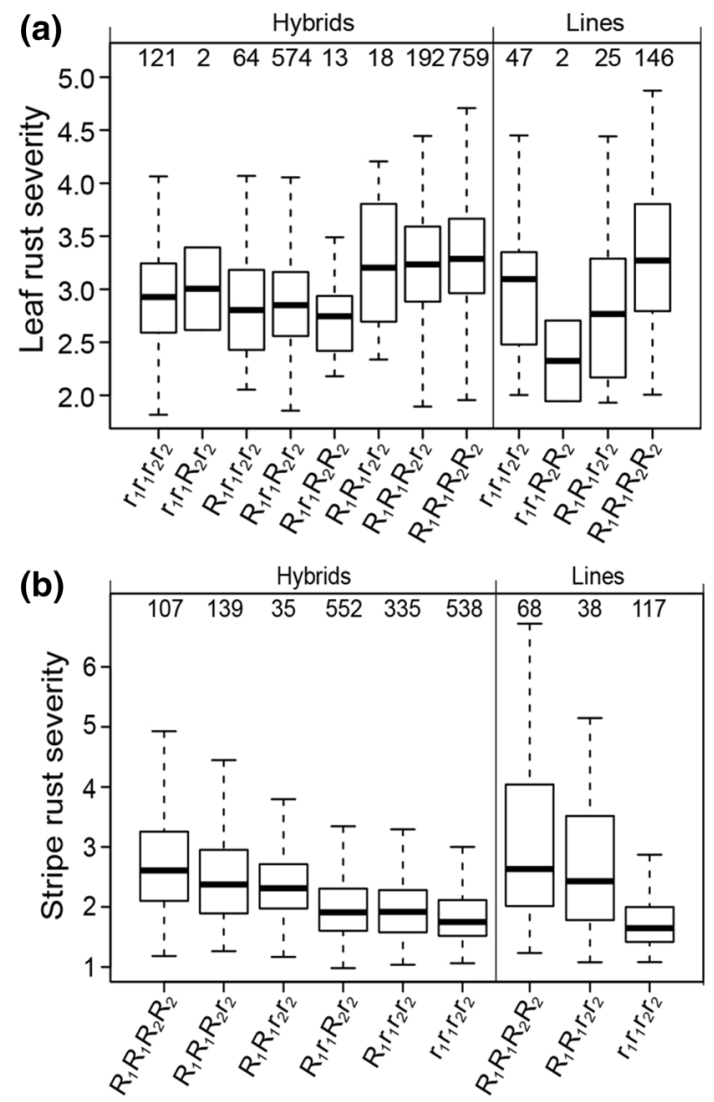

Fig. 7 Leaf rust (a) and stripe rust resistance (b) in dependence on genotypes detected by associated SNP markers. Box-whisker plots showing leaf rust severity of adult plants for different allele combinations at two resistance gene loci explaining each $\geq 12 \%$ of the phenotypic variation. SNP6846 $\left(r_{1} / R_{1}\right)$ and $\operatorname{SNP6577}\left(r_{2} / R_{2}\right)$ as well as SNP7071 $\left(r_{1} / R_{1}\right)$ and SNP8770 $\left(r_{2} / R_{2}\right)$ were observed for leaf and stripe rust resistance, respectively. $R$ refers to the allele supporting susceptibility, while $r$ represents the allele increasing resistance. The numbers at the top of each box refer to the observed numbers of hybrids (left) and parental inbred lines (right). Only homozygous parental lines and hybrids derived from them were considered

and septoria tritici blotch (0.29). This accordance confirms the high quality of the collected field data within this study.

\section{Specific hybrid combinations outperformed parental lines for leaf rust and stripe rust resistance}

The resistance level of male and female lines was comparable for leaf rust (Fig. 1; Suppl. Table 2). In contrast, females were more susceptible than males for stripe rust. For the female pool, $\sigma_{\mathrm{GCA}}^{2}$ contributes to $16.5 \%$ of the total genetic variance for stripe rust, which illustrates the potential to improve the resistance within the female pool. Females showed a higher phenotypic diversity than male parents, which was reflected by four and two times larger $\sigma_{\mathrm{GCA}}^{2}$ and the variance of phenotypic resistance performance against leaf rust and stripe rust, respectively.
Average midparent heterosis (MPH) amounted to $-1.6 \%$ and $-1.7 \%$ for leaf rust and stripe rust resistance, respectively. Better parent heterosis (BPH) was on average $12 \%$ and $26 \%$ for leaf rust and stripe rust resistance, respectively. In total 31\% (556 genotypes) and 22\% (399 genotypes) of the hybrids are more resistant than their better parent with a maximum of $-56 \%$ (improvement of 2.5 scores) and $-47 \%$ (improvement of 1.6 scores) for leaf rust and stripe rust resistance, respectively. Those results were in accordance with previous findings of Longin et al. (2013), who observed comparable amounts of average midparent heterosis for leaf rust and stripe rust resistance. In summary, hybrid heterosis for leaf rust and stripe rust resistance cannot be taken as generally valid concept. Specific hybrid combinations showing valuable heterosis effects for rust resistance are required to exploit the potential of hybrid wheat breeding. The large variation in heterosis levels leads to the conclusion that a clear understanding of the genetic architecture influencing the hybrid performance is essential to use the portfolio of resistance genes in an optimal way for hybrid breeding.

\section{Loci on 3D, 4A and 2A, 2B, 6A were strongly associated to leaf rust and stripe rust resistance, respectively}

Performing genome-wide association mapping with regard to leaf rust resistance revealed significantly associated loci on chromosomes 3D and 4A. The identified markers explained each a phenotypic variance ranging between $3-4 \%$ (4.45\% for the marker with the highest $P$ value), 9-12\% (12.3\% for the marker with the highest $P$ value), and 5-12\% (12.31\% for the marker with the highest $P$ value) (Suppl. Table 3). Chromosome 4A appears to be an important genome region with a high potential for leaf rust resistance in wheat. Correspondingly, promising loci were previously detected in association studies observing adult plant resistance in a set of American spring wheat (Gao et al. 2016) and in a diverse core set including winter and spring wheat ( $\mathrm{Li}$ et al. 2016) or considering seedling resistance in a wheat collection of CIMMYT (Juliana et al. 2018). The detected single nucleotide polymorphism (SNP) BobWhite_c47168_289 (SNP332) was also found as significantly associated with leaf rust resistance on wheat chromosome 4A by Gao et al. (2016). Significantly associated marker on chromosome 3D did not match with previous known gene functions connected to disease resistance (IWGSC 2018). Previous detected $L r$-genes on chromosome 3D did not occur in the European wheat population. Detected loci from this study are located inside genome regions of previous known nucleotide-binding site leucine-rich repeat (NBS-LRR) genes (IWGSC 2018). It would be obvious to treat the detected loci as candidate genes for the known leaf rust resistance genes Lr28 and Lr30, which were located on chromosome 4AL 
(McIntosh et al. 2013) while $L r 28$ is more likely because of its known dominant inheritance (McIntosh et al. 1982) in contrast to Lr30 (Kolmer 1996). Further work needs to be conducted for verification, because those resistance genes were not cloned so far and due to the large size of chromosome 4AL ( 300 Mb) NBS-LRR genes might occur in a high frequency (IWGSC 2018). Loci showing a strong association with stripe rust resistance were detected on chromosomes 2A, 2B, and 6A. However, identified markers on chromosome $2 \mathrm{~B}$ and $6 \mathrm{~A}$ did not match with previous known resistance genes (IWGSC 2018). There is no previous identified $\mathrm{Yr}$-gene on chromosome 6A. In contrast, marker-trait associations on chromosome $2 \mathrm{~B}$ are putative candidates for Yr27 (National BioResource Project 2018), which occur with a high frequency in the European wheat population. These SNPs explained 3-16\% (15.83\% for the marker with the highest $P$ value) of the phenotypic variance for markers on chromosome 2 A, $5-11 \%$ (10.92\% for the marker with the highest $P$ value) of the phenotypic variance for markers on chromosome $2 \mathrm{~B}$, and $1-3 \%$ (2.74\% for the marker with the highest $P$ value) of the phenotypic variance for markers on chromosome 6A, respectively (Suppl. Table 4). The importance of chromosome $2 \mathrm{~A}$ for seedling and adult plant resistance in wheat was also shown by Juliana et al. (2018) considering CIMMYT's bread wheat pool. Positions of detected loci on 2A are in coincidence with previous detected NBSLRR genes (IWGSC 2018). It is known that seven different stripe rust resistance genes are located on chromosome 2A (Yrl, Yr17, Yr32, Yr61, Yr56, Yr69, YrJ22) (National BioResource Project 2018). The European wheat population is segregating for the resistance genes $Y r 1, Y r 17$, and $Y r 32$, which are present at a high frequency especially in winter wheat varieties originating from France and Great Britain (National BioResource Project 2018). Yrl and Yr32 were reported to be located on the long chromosome arm of $2 \mathrm{~A}$ (Eriksen et al. 2004; National BioResource Project 2018), while in contrast, $\mathrm{Yr} 17$ originally translocated from Aegilops ventricosa could be identified on 2AS (Seah et al. 2001). The wheat chromosome $2 \mathrm{~A}$ has a total size of $780.8 \mathrm{Mb}$ (IWGSC 2018) and the identified loci related to a resistance function were located ranging from 7.5 to $21.2 \mathrm{Mb}$ (Table 3 ). On this account, it is obvious to assume that the few examined loci are located on the short chromosome arm of $2 \mathrm{~A}$ and were therefore most likely treated as candidate genes for $\mathrm{Yr} 17$.

\section{Leaf rust and stripe rust severity is not correlated in the analyzed European breeding material}

The comparison of genotypic values for leaf rust and stripe rust severity revealed no association between both traits. This is in contrast to previous findings, which reported the presence of a few pleiotropic genes in wheat causing resistance for both leaf rust and stripe rust. Published completely linked genes are Lr34/Yr18 (McIntosh 1992), Lr46/Yr29 (William et al. 2003), Lr27/Yr30 (Singh 1992), and Lr67/Yr46 (Herrera-Foessel et al. 2011) located on chromosome 7DS, 1BL, 3BS, and 4DL, respectively. Those pleiotropic genes are predominantly present in spring wheat varieties of North and South America (National BioResource Project 2018) and were identified in this study, therefore. However, $L r 34 / Y r 18$ and $L r 27 / Y r 30$ have been implemented in many wheat cultivars, but $\operatorname{Lr} 34$ causes extremely small quantitative resistance effects under field conditions, which are macroscopically hardly visible. The resistance induced by $L r 27$ was broken down by many isolates of the natural occurring leaf rust populations (Dadkhodaie et al. 2011) and was therefore not detected. This leads to the assumption that pleiotropic genes causing resistance against both rust diseases are absent or inefficient in European winter wheat varieties and explains the lack of an association between leaf rust and stripe rust resistance in our study.

\section{Improved resistances can be achieved through hybrid breeding by fixing leaf rust and stripe rust resistance genes in opposite parental pools}

To reach an increased resistance level of hybrids with the help of detected recessive resistance genes, it would be necessary to fix those genes in both parental pools. In this case improving resistance is not simplified by hybrid compared to line breeding. In contrast, 72 and 56 SNPs with significant dominance effects were identified overall influencing leaf rust and stripe rust resistance, respectively. The majority of those markers (60\% for leaf rust and $98 \%$ for stripe rust) showed higher absolute additive than absolute dominance effects. The dominance effect was negative for all detected markers, leading to a decreased rust susceptibility in the hybrids compared to the midparent performance. Based on the amount and the relation of additive and dominance effects, most marker loci may be assumed as partial dominant for both, leaf rust and stripe rust resistance. In correspondence to that, Gowda et al. (2014) detected partial dominance for leaf rust and stripe rust resistance studying a hybrid winter wheat set. Despite of the frequent occurrence of partial dominance, a fixation of resistance genes in only one parental pool may beneficial. The partial dominance pushing the resistance to a higher level. Therefore, fixing the favorable resistance allele in one parental pool would minimize breeding efforts and save resources, while resulting in a gain of rust resistance (Fig. 7). A rust resistance based on various loci would maximize the resistance benefit for heterozygous hybrids and would have additionally a positive effect on the effectiveness as well as the durability of the resistance against fast adapting rust populations. Furthermore, $8 \%$ of the examined marker loci showed a 
complete dominance for leaf rust resistance, while $32 \%$ and $2 \%$ of the loci represented overdominance for leaf and stripe rust resistance, respectively (Suppl. Tables 3, 4). For those marker loci, the dominant resistance gene should be fixed in only one parental pool for the production of resistant hybrids. This would simplify the accumulation of different resistance genes within a hybrid due to the combination of parental inbred lines carrying different resistance loci (Longin et al. 2013) and is therefore a big advantage of the hybrid breeding strategy. In summary, the requirement for a desirable and profitable fixation of resistance genes in only one parental pool is the existence of specific hybrid combinations showing favorable partial or complete dominance for disease resistance, and those genes are needed to exploit the potential of hybrid wheat breeding. To fulfill this and identify favorable hybrids, a detailed knowledge of the degree of dominance for the relevant resistance genes is needed.

Acknowledgements Open Access funding provided by Projekt DEAL. The experimental work was supported by the German Federal Ministry of Food and Agriculture within the ZUCHTWERT Project (Grant FKZ0103010). The Federal Ministry of Education and Research of Germany is acknowledged for funding UB (Grant No. FKZ031B0184B).

Author contribution statement JCR and UB designed the study; MG provided genotypic data; PT, PHGB, and YZ curated phenotypic and genomic data; GL and UB performed the analyses; UB and JCR wrote the paper with input from all co-authors.

\section{Compliance with ethical standards}

Conflict of interest The authors declare that they have no conflict of interest.

Ethical standard The authors declare that the experiments comply with the current laws of Germany.

Open Access This article is licensed under a Creative Commons Attribution 4.0 International License, which permits use, sharing, adaptation, distribution and reproduction in any medium or format, as long as you give appropriate credit to the original author(s) and the source, provide a link to the Creative Commons licence, and indicate if changes were made. The images or other third party material in this article are included in the article's Creative Commons licence, unless indicated otherwise in a credit line to the material. If material is not included in the article's Creative Commons licence and your intended use is not permitted by statutory regulation or exceeds the permitted use, you will need to obtain permission directly from the copyright holder. To view a copy of this licence, visit http://creativecommons.org/licenses/by/4.0/.

\section{References}

Boeven PHG, Zhao Y, Thorwarth P, Liu F, Maurer HP, Gils M, Schachschneider R, Schacht J, Ebmeyer E, Kazman E, Mirdita V, Dörnte J, Kontowski S, Horbach R, Cöster H, Holzapfel J, Jacobi A, Ramgraber L, Reinbrecht C, Starck N, Varenne P, Starke A,
Schürmann F, Ganal M, Polley A, Hartung J, Beier S, Scholz U, Longin CFH, Reif JC, Jiang Y, Würschum T (2020) Negative dominance and dominance-by-dominance epistatic effects reduce grain-yield heterosis in wide crosses in wheat. Under review

Bolton MD, Kolmer JA, Garvin DF (2008) Wheat leaf rust caused by Puccinia triticina. Mol Plant Pathol 9:563-575

Bundessortenamt (2000) Richtlinien für die Durchführung von landwirtschaftlichen Wertprüfungen und Sortenversuchen. LandbuchVerlag, Hannover

Chen X (2005) Epidemiology and control of stripe rust [Puccinia striiformis f. sp. tritici] on wheat. Can J Plant Path 27:314-337

Chen X (2013) High-temperature adult-plant resistance, key for sustainable control of stripe rust. Am J Plant Sci 4:608

Dadkhodaie NA, Singh D, Park RF (2011) Characterisation of resistance to leaf rust in an international bread wheat nursery. J Plant Pathol 93:627-641

Eriksen L, Afshari F, Christiansen MJ, McIntosh RA, Jahoor A, Wellings CR (2004) Yr32 for resistance to stripe (yellow) rust present in the wheat cultivar Carstens V. Theor Appl Genet 108:567-575

FAO (2019) FAOSTAT. http://www.fao.org/faostat/. Accessed 10 Jan 2019

Gao L, Turner MK, Chao S, Kolmer J, Anderson JA (2016) Genome wide association study of seedling and adult plant leaf rust resistance in elite spring wheat breeding lines. PLoS ONE 11:e0148671

Gilmour AR, Gogel B, Cullis B, Thompson R (2009) ASReml user guide release 3.0. VSN International Ltd, Hemel Hempstead

Gowda M, Zhao Y, Würschum T, Longin CF, Miedaner T, Ebmeyer E, Schachschneider R, Kazman E, Schacht J, Martinant J (2014) Relatedness severely impacts accuracy of marker-assisted selection for disease resistance in hybrid wheat. Heredity 112:552

He S, Zhao Y, Mette MF, Bothe R, Ebmeyer E, Sharbel TF, Reif JC, Jiang Y (2015) Prospects and limits of marker imputation in quantitative genetic studies in European elite wheat (Triticum aestivum L.). BMC Genom 16:168

Herrera-Foessel SA, Lagudah ES, Huerta-Espino J, Hayden MJ, Bariana HS, Singh D, Singh RP (2011) New slow-rusting leaf rust and stripe rust resistance genes Lr67 and Yr46 in wheat are pleiotropic or closely linked. Theor Appl Genet 122:239-249

Huerta-Espino J, Singh R, German S, McCallum B, Park R, Chen WQ, Bhardwaj S, Goyeau H (2011) Global status of wheat leaf rust caused by Puccinia triticina. Euphytica 179:143-160

International Wheat Genome Sequencing Consortium (IWGSC) (2018) Shifting the limits in wheat research and breeding using a fully annotated reference genome. Science 361:eaar7191

Jiang Y, Schmidt RH, Zhao Y, Reif JC (2017) A quantitative genetic framework highlights the role of epistatic effects for grain-yield heterosis in bread wheat. Nat Genet 49:1741-1746

Juliana P, Singh RP, Singh PK, Poland JA, Bergstrom GC, HuertaEspino J, Bhavani S, Crossa J, Sorrells ME (2018) Genome-wide association mapping for resistance to leaf rust, stripe rust and tan spot in wheat reveals potential candidate genes. Theor Appl Genet 131:1405-1422

Kolmer J (1996) Genetics of resistance to wheat leaf rust. Annu Rev Phytopathol 34:435-455

Li G, Xu X, Bai G, Carver BF, Hunger R, Bonman JM, Kolmer J, Dong H (2016) Genome-wide association mapping reveals novel QTL for seedling leaf rust resistance in a worldwide collection of winter wheat. Plant Genome 2016:9

Liu G, Zhao Y, Gowda M, Longin CFH, Reif JC, Mette MF (2016) Predicting hybrid performances for quality traits through genomicassisted approaches in Central European wheat. PLoS ONE 11:e0158635

Longin CFH, Mühleisen J, Maurer HP, Zhang H, Gowda M, Reif JC (2012) Hybrid breeding in autogamous cereals. Theor Appl Genet 125:1087-1096 
Longin CFH, Gowda M, Mühleisen J, Ebmeyer E, Kazman E, Schachschneider R, Schacht J, Kirchhoff M, Zhao Y, Reif JC (2013) Hybrid wheat: quantitative genetic parameters and consequences for the design of breeding programs. Theor Appl Genet 126:2791-2801

McIntosh R (1992) Close genetic linkage of genes conferring adultplant resistance to leaf rust and stripe rust in wheat. Plant Pathol 41:523-527

McIntosh R, Miller T, Chapman V (1982) Cytogenetical studies in wheat XII. Lr28 for resistance to Puccinia recindita and Sr34 for resistance to $P$. graminis tritici. Z Pflanzenzüchtung 89:295-306

McIntosh R, Wellings C, Park R (1995) Wheat rusts: an atlas of resistance genes. Csiro Publishing, Melbourne

McIntosh R, Devos K, Dubcovsky J, Rogers W, Morris C, Appers R, Anderson O (2005) Catalogue of gene symbols for wheat 2005 Supplement. https://shigen.nig.ac.jp/wheat/komugi/genes/macge ne/supplement2005.pdf. Accessed 6 Mar 2020

McIntosh R, Dubcovsky J, Rogers W, Morris C, Xia X (2009) Catalogue of gene symbols for wheat 2009 Supplement. https://shige n.nig.ac.jp/wheat/komugi/genes/macgene/supplement2009.pdf. Accessed 6 Mar 2020

McIntosh R, Dubcovsky J, Rogers W, Morris C, Appels R, Xia X (2013) Wheat gene catalouge 2013. https://wheat.pw.usda.gov/ GG2/Triticum/wgc/2013/. Accessed 16 Jan 2019

McIntosh R, Dubcovsky J, Rogers W, Morris C, Appels R, Xia X (2015) Catalogue of gene symbols for wheat 2015-2016 Supplement. https://shigen.nig.ac.jp/wheat/komugi/genes/macgene/suppl ement2015.pdf. Accessed 6 Mar 2020

McIntosh R, Dubcovsky J, Rogers W, Morris C, Appels R, Xia X (2017) Catalogue of gene symbols for wheat 2017 Supplement. https://shigen.nig.ac.jp/wheat/komugi/genes/macgene/supplement 2017.pdf. Accessed 6 Mar 2020

Miedaner T, Zhao Y, Gowda M, Longin CFH, Korzun V, Ebmeyer E, Kazman E, Reif JC (2013) Genetic architecture of resistance to Septoria tritici blotch in European wheat. BMC Genom 14:858

Mühleisen J, Piepho H-P, Maurer HP, Longin CFH, Reif JC (2014) Yield stability of hybrids versus lines in wheat, barley, and triticale. Theor Appl Genet 127:309-316

National BioResource Project (2018) KOMUGI wheat genetic resources database. https://shigen.nig.ac.jp/wheat/komugi/. Accessed 25 Jul 2018

Peña-Bautista RJ, Hernandez-Espinosa N, Jones JM, Guzmán C, Braun HJ (2017) CIMMYT series on carbohydrates, wheat, grains, and health: wheat-based foods: their global and regional importance in the food supply, nutrition, and health. Cereal Foods World 62:231-249

Prescott J, Burnett P, Saari E, Ransom J, Bowman J, De Milliano W, Singh R, Geleta AB (1986) Wheat diseases and pests: a guide for field identification. CIMMYT, Mexico

R Development Core Team (2014) R: a language and environment for statistical computing. http://www.R-project.org
Schulthess AE, Zhao Y, Longin CFH, Reif JC (2018) Advantages and limitations of multiple-trait genomic prediction for Fusarium head blight severity in hybrid wheat (Triticum aestivum L.). Theor Appl Genet 131:685-701

Schwessinger B (2017) Fundamental wheat stripe rust research in the 21st century. New Phytol 213:1625-1631

Seah S, Bariana H, Jahier J, Sivasithamparam K, Lagudah ES (2001) The introgressed segment carrying rust resistance genes Yr17, $\mathrm{Lr} 37$ and $\mathrm{Sr} 38$ in wheat can be assayed by a cloned disease resistance gene-like sequence. Theor Appl Genet 102:600-605

Singh RP (1992) Genetic association of leaf rust resistance gene Lr34 with adult plant resistance to stripe rust in bread wheat. Phytopathology 82:835-838

Singh RP, Huerta-Espino J, William HM (2005) Genetics and breeding for durable resistance to leaf and stripe rusts in wheat. Turk J Agric For 29:121-127

Stein N, Herren G, Keller B (2001) A new DNA extraction method for high-troughput marker analysis in a large-genome species such as Triticum aestivum. Plant Breeding 120:354-356

Wang S, Wong D, Forrest K, Allen A, Chao S, Huang BE, Maccaferri M, Salvi S, Milner SG, Cattivelli L, Mastrangelo AM, Whan A, Stephen S, Barker G, Wieseke R, Plieske J, International Wheat Genome Sequencing Consortium, Lillemo M, Mather D, Appels R, Dolferus R, Brown-Guedira G, Korol A, Akhunova AR, Feuillet C, Salse J, Morgante M, Pozniak C, Luo MC, Dvorak J, Morell M, Dubcovsky J, Ganal M, Tuberosa R, Lawley C, Mikoulitch I, Cavanagh C, Edwards KJ, Hayden M, Akhunov E (2014) Characterization of polyploid wheat genomic diversity using a highdensity 90,000 single nucleotide polymorphism array. Plant Biotechnol J 12:787-796

Weir BS (1996) Genetic data analysis: methods for discrete population genetic data. Sinauer Associates, Sunderland

Wellings CR (2011) Global status of stripe rust: a review of historical and current threats. Euphytica 179:129-141

William H, Singh R, Huerta-Espino J, Islas S, Hoisington D (2003) Molecular marker mapping of leaf rust resistance gene Lr46 and its association with stripe rust resistance gene Yr29 in wheat. Phytopathology 93:153-159

Zhao Y, Gowda M, Würschum T, Longin CFH, Korzun V, Kollers S, Schachschneider R, Zeng J, Fernando R, Dubcovsky J (2013) Dissecting the genetic architecture of frost tolerance in Central European winter wheat. J Exp Bot 64:4453-4460

Publisher's Note Springer Nature remains neutral with regard to jurisdictional claims in published maps and institutional affiliations. 